\title{
BMJ Open SARS-CoV-2 antibody prevalence and correlates of six ethnic groups living in Amsterdam, the Netherlands: a population-based cross-sectional study, June-October 2020
}

\author{
Liza Coyer (1) , ${ }^{1,2}$ Anders Boyd, ${ }^{1,3}$ Janke Schinkel, ${ }^{4}$ Charles Agyemang, ${ }^{5}$ \\ Henrike Galenkamp, ${ }^{5}$ Anitra D M Koopman, ${ }^{5}$ Tjalling Leenstra, ${ }^{1}$ \\ Eric P Moll van Charante, ${ }^{5,6}$ Bert-Jan $\mathrm{H}$ van den Born, ${ }^{5,7}$ Anja Lok, ${ }^{8}$ \\ Arnoud Verhoeff, ${ }^{9,10}$ Aeilko $\mathrm{H}$ Zwinderman, ${ }^{11}$ Suzanne Jurriaans, ${ }^{4}$ \\ Lonneke A van Vught, ${ }^{6,12}$ Karien Stronks, ${ }^{5}$ Maria Prins ${ }^{1,2}$
}

To cite: Coyer L, Boyd A, Schinkel J, et al. SARSCoV-2 antibody prevalence and correlates of six ethnic groups living in Amsterdam, the Netherlands: a populationbased cross-sectional study, June-October 2020. BMJ Open 2022;12:e052752. doi:10.1136/ bmjopen-2021-052752

- Prepublication history and additional supplemental material for this paper are available online. To view these files, please visit the journal online (http://dx.doi.org/10.1136/ bmjopen-2021-052752).

Received 23 April 2021 Accepted 08 December 2021

Check for updates

(c) Author(s) (or their employer(s)) 2022. Re-use permitted under CC BY-NC. No commercial re-use. See rights and permissions. Published by BMJ.

For numbered affiliations see end of article.

Correspondence to

Liza Coyer;

Icoyer@ggd.amsterdam.nl

\section{ABSTRACT}

Objectives It has been suggested that ethnic minorities have been disproportionally affected by the COVID-19. We aimed to determine whether prevalence and correlates of past SARS-CoV-2 exposure varied between six ethnic groups in Amsterdam, the Netherlands.

Design, setting, participants Participants aged 25-79 years enrolled in the Healthy Life in an Urban Setting population-based prospective cohort $(n=16889)$ were randomly selected within ethnic groups and invited to participate in a cross-sectional COVID-19 seroprevalence substudy.

Outcome measures We tested participants for SARSCoV-2-specific antibodies and collected information on SARS-CoV-2 exposures. We estimated prevalence and correlates of SARS-CoV-2 exposure within ethnic groups using survey-weighted logistic regression adjusting for age, sex and calendar time.

Results Between 24 June and 9 0ctober 2020, we included 2497 participants. Adjusted SARS-CoV-2 seroprevalence was comparable between ethnic Dutch (24/498; 5.1\%, 95\% Cl 2.8\% to 7.4\%), South-Asian Surinamese $(22 / 451 ; 4.9 \%, 95 \% \mathrm{Cl} 2.2 \%$ to $7.7 \%)$, African Surinamese $(22 / 400 ; 8.3 \%, 95 \% \mathrm{Cl} 3.1 \%$ to $13.6 \%$ ), Turkish (30/408; $7.9 \%, 95 \% \mathrm{Cl} 4.4 \%$ to $11.4 \%)$ and Moroccan (32/391; 7.2\%, 95\% Cl $4.2 \%$ to $10.1 \%$ ) participants, but higher among Ghanaians $(95 / 327 ; 26.3 \%$, $95 \% \mathrm{Cl} 18.5 \%$ to $34.0 \%$ ). $57.1 \%$ of SARS-CoV-2-positive participants did not suspect or were unsure of being infected, which was lowest in African Surinamese (18.2\%) and highest in Ghanaians (90.5\%). Correlates of SARSCoV-2 exposure varied across ethnic groups, while the most common correlate was having a household member suspected of infection. In Ghanaians, seropositivity was associated with older age, larger household sizes, living with small children, leaving home to work and attending religious services.

Conclusions No remarkable differences in SARS-CoV-2 seroprevalence were observed between the largest ethnic groups in Amsterdam after the first wave of infections.

\section{Strengths and limitations of this study}

- Our study used data from a large population-based sample, including participants belonging to most major ethnic groups in Amsterdam (ie, South-Asian Surinamese, African Surinamese, Ghanaian, Turkish, Moroccan).

- We measured SARS-CoV-2 antibodies in participants regardless of COVID-19-related symptoms and obtained individual-level data on correlates of infection.

- Although response rates varied between ethnic groups, the characteristics of included individuals were largely similarly distributed to those non-included.

- Our study did not include undocumented people and people from other ethnic groups.

The higher infection seroprevalence observed among Ghanaians, which passed mostly unnoticed, warrants wider prevention efforts and opportunities for nonsymptom-based testing.

\section{INTRODUCTION}

Data from the UK and USA suggest that certain ethnic minority populations have been disproportionally affected by COVID-19, caused by SARS-CoV-2. In both countries, a relatively higher number of SARS-CoV-2 PCRpositive or clinically diagnosed COVID-19 cases were observed among ethnic minority groups, particularly people of African and Asian descent. ${ }^{1-3}$ The underlying causes for these disparities might include workrelated exposure, housing conditions, access to healthcare, help-seeking behaviour and language proficiency. ${ }^{4-6}$ 
Little is known about ethnic differences in SARS-CoV-2 infections outside the UK and USA. This is of particular concern for larger cities in Europe, including the Dutch capital Amsterdam, where half of the population comprises migrants, including people with foreign-born parents. ${ }^{7}$ Amsterdam witnessed its first confirmed case of SARS-CoV-2 on 29 February 2020 and by 31 December 2020, there were more than 50000 confirmed infections, 1300 COVID-19-related hospitalisations and 500 COVID19-related deaths. ${ }^{8}$ During the first wave of COVID-19, COVID-19-related hospitalisation rates were higher in individuals who have migrated from lower and middleincome countries compared with ethnic Dutch individuals in Amsterdam, with the highest rates observed in individuals of Ghanaian or Turkish ethnic origin. ${ }^{9}$ However, it was unclear if these differences resulted from differences in acquiring infection, differences in disease severity after infection, or both. If SARS-CoV-2 infection prevalence is increased in specific ethnic groups, targeted prevention measures could be instated or improved to help minimise the risk of further transmission.

Ethnic differences in SARS-CoV-2 infection prevalence could be studied using COVID-19 notification registries. ${ }^{10}$ However, since the testing policy in the Netherlands has changed several times and until 1 June 2020, testing was largely restricted to symptomatic healthcare workers or those living or working in long-term care facilities, these data are prone to differential testing uptake. ${ }^{9}$ Ethnic differences in testing uptake could be further exacerbated by testing access, willingness to test and disease perceptions. ${ }^{41-13}$ Another limitation of registries is that migration background is often missing. Other data are therefore needed to estimate seroprevalence within specific ethnic groups in Amsterdam.

The Healthy Life in an Urban Setting (HELIUS) study is a large, population-based cohort study among six different ethnic groups, which was established with the aim to investigate mechanisms underlying the impact of ethnicity on communicable and non-communicable diseases. ${ }^{14}$ From individuals actively enrolled in this study, we determined the prevalence and correlates of exposure to SARS-CoV-2 between the largest ethnic groups in Amsterdam.

\section{METHODS}

\section{Study design and population}

The HELIUS study is a multiethnic cohort study conducted in Amsterdam, the Netherlands, which focuses on cardiovascular disease, mental health and infectious diseases. Detailed procedures have been previously described. ${ }^{14}$ Briefly, HELIUS includes persons of Dutch, South-Asian Surinamese, African Surinamese, Ghanaian, Moroccan and Turkish origin, aged between 18 and 70 years at inclusion. A random sample of persons, stratified by ethnic origin, was taken from the municipality register of Amsterdam and subjects were invited to participate. Between January 2011 and December 2015, a total of
24789 individuals were included. ${ }^{14}$ Participants filled in a self-administered questionnaire and underwent a physical examination during which biological samples were obtained.

Ethnicity was defined according to the country of birth of the participant and their parents. ${ }^{14}$ Participants were considered to be of non-Dutch ethnic origin if (1) they were born abroad and had at least one parent born abroad (first generation) or (2) they were born in the Netherlands but both their parents were born abroad (second generation). Participants of Dutch origin were born in the Netherlands with both parents who were born in the Netherlands. Surinamese participants were further classified as African Surinamese, South-Asian Surinamese and Javanese/other/unknown Surinamese, based on self-reporting.

A cross-sectional, serological substudy was performed in participants of the HELIUS study from 24 June to 9 October 2020. HELIUS participants who were still in follow-up and belonged to one of the six ethnic groups included in the substudy $(\mathrm{n}=16889)$ were randomly selected within each ethnic group and asked to participate in the substudy. Assuming a seroprevalence of 5\% in the Dutch ethnic origin group, a sample size of 430 per group $(n=2580)$ would be required to detect at least a two times higher prevalence between Dutch and a given ethnic minority group, with type I error at $5 \%$ and power at $80 \%$. Recruitment into the substudy continued until the target sample size of 430 per group was achieved for all groups or the recruitment period ended (October 2020). Serum samples for assessment of SARS-CoV-2 antibodies were collected by venipuncture and stored at $-20^{\circ} \mathrm{C}$. Trained interviewers asked participants questions on uptake of COVID-19-related prevention measures, potential exposure, infection, symptoms and disease.

\section{Outcomes}

SARS-CoV-2 exposure was determined by the presence of SARS-CoV-2 antibodies. SARS-CoV-2-specific antibodies were determined using the WANTAI SARS-CoV-2 Ab ELISA (Wantai Biological Pharmacy Enterprise, Beijing, China) according to the manufacturer's instructions. This ELISA detects IgA, IgM and IgG against the receptorbinding domain of the S-protein of SARS-CoV-2. ${ }^{15}$

\section{Correlates}

We defined the following potential correlates: from the baseline visit of the HELIUS study-demographics (ie, age, sex, ethnicity, migration generation, city district), socioeconomic factors (ie, educational level, working status, occupational level, number of people in household), access-to-healthcare indicators (ie, proficiency with Dutch language, health literacy); from the COVID-19 substudy visit_-job setting, household members, suspected being infected, thinking household member/steady partner was infected, household member hospitalised for COVID-19, type of people living in household, travelling abroad in 2020 and COVID-19 behaviours in the 
past week (ie, number of times leaving the house, type of locations visited, number of visitors, frequency of using public transportation).

\section{Statistical analysis}

SARS-CoV-2 seroprevalence, along with 95\% CIs, was modelled per ethnic group using univariable logistic regression. Seroprevalence was then modelled per ethnic group while correcting for sampling, accounting for the population structure of ethnic groups in Amsterdam (ie, poststratification) and adjusting for differences in age, sex and calendar time (before/after 15 August 2020, based on the onset of the second wave of SARS-CoV-2 infections in the Netherlands ${ }^{8}$ ) between ethnic groups (online supplemental materials). The mean and 95\% CI of predicted seroprevalence was plotted over age in years.

To identify the correlates of past SARS-CoV-2 infection within ethnic groups, univariable associations between potential correlates and SARS-CoV-2 seropositivity were evaluated. The ORs comparing the odds of seroprevalence across levels of each determinant, and their 95\% CIs, were estimated using logistic regression. $\mathrm{P}$ values were obtained using the Wald $\chi^{2}$ test. All covariates with a $p$ value $\leq 0.2$ in univariable analyses were then included in a multivariable model and after assessing covariate distributions and collinearity, variables with a $p$ value $\geq 0.05$ above this threshold were removed in backward stepwise fashion until only variables with a $p$ value $<0.05$ were retained in a final multivariable model. All models included sampling and poststratification weights. We forced calendar time in all models.

Statistical significance was defined at a $\mathrm{p}$ value $<0.05$. We did not correct for multiple testing and results should be considered exploratory. ${ }^{16}$ All analyses were conducted using Stata V.15.1 (StataCorp, College Station, Texas, USA).

\section{Patient and public involvement}

There was no patient or public involvement in the development of the research questions, outcome measures, study design and recruitment/conduct for the current study. However, the parent HELIUS study employed several recruitment strategies to enhance enrolment of all eligible ethnic groups, for example, by involving faith communities (churches and mosques) and community leaders to endorse the study, conducting at-home visits to non-Dutch persons who did not respond to the written invitation letter and by providing, on request, additional information or assistance in completing the questionnaire from a trained ethnically matched same-sex interviewer who spoke their preferred language. Results of the current study were disseminated to the involved communities following preliminary results to improve prevention and care. HELIUS study participants were invited for online seminars during which results were presented and discussed. Meetings were held with community leaders, general practitioners serving the population at risk and local prevention teams. The prevention teams in turn developed prevention measures in cocreation with the community and met with key stakeholders such as employers to discuss their role.

\section{RESULTS}

\section{Study population}

Of the 16889 HELIUS participants who were in active follow-up in 2019-2020, a total of 11080 (65.6\%) were invited (online supplemental figure S1). Of these, 2497 $(22.5 \%)$ were included in the COVID-19 substudy. The response rate varied across ethnic groups, from 15.3\% to $17.2 \%$ among Ghanaian, Turkish or Moroccan participants to $49.9 \%$ among Dutch participants. Detailed information on differences between HELIUS participants who were and were not invited, and between invited participants who were and were not included, is presented in online supplemental table S1. Briefly, invited individuals who were included had obtained a slightly higher educational level, were more likely to be employed and were more likely to have adequate health literacy level compared with those who were invited but not included.

Number included per month within ethnic groups is presented in online supplemental figure S2. Of 2497 included participants, $503(20.1 \%)$ were of Dutch origin, $453(18.1 \%)$ South-Asian Surinamese, 407 (16.3\%) African Surinamese, 331 (13.3\%) Ghanaian, 409 (16.4\%) Turkish and 394 (15.8\%) Moroccan (online supplemental table S1, table 1). The median age of included participants was 54 (IQR: 44-61) and 56.6\% were female. In the 1994 participants of non-Dutch origin, the percentage of first-generation migrants was lowest in the Turkish group $(74.8 \%)$ and highest in the Ghanaian group (98.2\%). Dutch participants were the most likely to have a higher vocational or university degree $(67.0 \%)$ and be employed $(75.5 \%)$ compared with other ethnicities.

\section{SARS-CoV-2 seroprevalence}

Of 2497 included, 2483 (99.4\%) participants had a SARSCoV-2 antibody test result. Of these 2483, a total of 225 were positive, 2248 negative and 8 had an equivocal test result. The distribution of signal-to-cut-off ratios for positive test results is shown per ethnic group in online supplemental figure S3. The proportion with a positive result did not increase over time in any of the ethnic groups, except for the South-Asian Surinamese group (online supplemental figure S2).

Unadjusted and adjusted seroprevalence estimates per ethnic group are provided in figure 1. Adjusted seroprevalence was comparable between the Dutch $(24 / 498 ; 5.1 \%$, $95 \%$ CI $2.8 \%$ to $7.4 \%)$, South-Asian Surinamese (22/451; $4.9 \%, 95 \%$ CI $2.2 \%$ to $7.7 \%)$, African Surinamese (22/400; $8.3 \%, 95 \%$ CI $3.1 \%$ to $13.6 \%)$, Turkish (30/408; $7.9 \%, 95 \%$ CI $4.4 \%$ to $11.4 \%$ ) and Moroccan (32/391; $7.2 \%, 95 \%$ CI $4.2 \%$ to $10.1 \%$ ) groups, but higher in the Ghanaian group compared with all other groups (95/327; $26.3 \%, 95 \%$ CI $18.5 \%$ to $34.0 \%, \mathrm{p}<0.001)$. 
Table 1 Characteristics of the HELIUS participants included in the COVID-19 study, by ethnic group ( $n=2497)$, Amsterdam, the Netherlands, 24 June to 9 October 2020

\begin{tabular}{|c|c|c|c|c|c|c|c|}
\hline & $\begin{array}{l}\begin{array}{l}\text { Dutch } \\
(n=503)\end{array} \\
\end{array}$ & $\begin{array}{l}\text { South-Asian } \\
\text { Surinamese } \\
(n=453)\end{array}$ & $\begin{array}{l}\text { African } \\
\text { Surinamese } \\
(n=407)\end{array}$ & $\begin{array}{l}\text { Ghanaian } \\
(\mathrm{n}=331)\end{array}$ & $\begin{array}{l}\text { Turkish } \\
(\mathrm{n}=409)\end{array}$ & $\begin{array}{l}\text { Moroccan } \\
(\mathrm{n}=394)\end{array}$ & \\
\hline Characteristic & n (\%) & n (\%) & n (\%) & n (\%) & n (\%) & n (\%) & P value* \\
\hline Male & $237(47.1)$ & $179(39.5)$ & $165(40.5)$ & $145(43.8)$ & $184(45.0)$ & $173(43.9)$ & 0.19 \\
\hline Female & $266(52.9)$ & $274(60.5)$ & $242(59.5)$ & $186(56.2)$ & $225(55.0)$ & $221(56.1)$ & \\
\hline \multicolumn{8}{|l|}{ Migration generation } \\
\hline 1st & NA & $370(81.7)$ & $355(87.2)$ & 325 (98.2) & $306(74.8)$ & $300(76.1)$ & $<0.001$ \\
\hline $2 n d$ & NA & $83(18.3)$ & $52(12.8)$ & $6(1.8)$ & $103(25.2)$ & $94(23.9)$ & \\
\hline \multicolumn{8}{|l|}{ City district $†$} \\
\hline South & $112(22.3)$ & $32(7.1)$ & $26(6.4)$ & $8(2.4)$ & $30(7.3)$ & $38(9.6)$ & \\
\hline New-West & $45(8.9)$ & $111(24.5)$ & $52(12.8)$ & $18(5.4)$ & $233(57.0)$ & $147(37.3)$ & \\
\hline South-East & $65(12.9)$ & $228(50.3)$ & $190(46.7)$ & $253(76.4)$ & $5(1.2)$ & $19(4.8)$ & \\
\hline Other/missing & $7(1.4)$ & $6(1.3)$ & $5(1.2)$ & $3(0.9)$ & $6(1.5)$ & $3(0.8)$ & \\
\hline \multicolumn{8}{|l|}{ Educational level† } \\
\hline No school/elementary school & $10(2.0)$ & $56(12.4)$ & $15(3.7)$ & $78(23.6)$ & $78(19.1)$ & $90(22.8)$ & $<0.001$ \\
\hline $\begin{array}{l}\text { Lower vocational/lower secondary } \\
\text { school }\end{array}$ & $56(11.1)$ & $156(34.4)$ & $124(30.5)$ & $128(38.7)$ & $84(20.5)$ & $64(16.2)$ & \\
\hline $\begin{array}{l}\text { Intermediary vocational/intermediary } \\
\text { secondary school }\end{array}$ & $99(19.7)$ & $137(30.2)$ & $142(34.9)$ & $73(22.1)$ & $124(30.3)$ & $125(31.7)$ & \\
\hline Disabled & $11(2.2)$ & $39(8.6)$ & $24(5.9)$ & $28(8.5)$ & $27(6.6)$ & $22(5.6)$ & \\
\hline Unknown/missing & $1(0.2)$ & $6(1.3)$ & $4(1.0)$ & $30(9.0)$ & $14(3.4)$ & $23(5.8)$ & \\
\hline \multicolumn{8}{|l|}{ Occupational level† } \\
\hline Elementary occupations & $5(1.0)$ & $36(7.9)$ & $22(5.4)$ & $162(48.9)$ & $52(12.7)$ & $46(11.7)$ & $<0.001$ \\
\hline Lower occupations & $46(9.1)$ & $127(28.0)$ & $101(24.8)$ & $69(20.8)$ & $102(24.9)$ & $92(23.4)$ & \\
\hline Intermediary occupations & $107(21.3)$ & $143(31.6)$ & $146(35.9)$ & $21(6.3)$ & $88(21.5)$ & 94 (23.9) & \\
\hline Higher occupations & $203(40.4)$ & $79(17.4)$ & $91(22.4)$ & $11(3.3)$ & $51(12.5)$ & $65(16.5)$ & \\
\hline Scientific occupations & 115 (22.9) & $20(4.4)$ & $19(4.7)$ & $6(1.8)$ & $32(7.8)$ & $10(2.5)$ & \\
\hline Missing & $27(5.4)$ & $48(10.6)$ & $28(6.9)$ & $62(18.7)$ & $84(22.5)$ & $87(22.1)$ & \\
\hline \multicolumn{8}{|l|}{ Job setting $\ddagger \S$} \\
\hline No job/caretaker only & 117 (23.3) & $144(31.8)$ & $120(29.5)$ & $90(27.2)$ & $138(33.7)$ & $132(33.5)$ & $<0.001$ \\
\hline Job with no contact within $1.5 \mathrm{~m}$ & $96(19.1)$ & $65(14.3)$ & $39(9.6)$ & $66(19.9)$ & $67(16.4)$ & $54(13.7)$ & \\
\hline Other job with contact within $1.5 \mathrm{~m}$ & $145(28.8)$ & $154(34.0)$ & $131(32.2)$ & $115(34.7)$ & $130(31.8)$ & $114(28.9)$ & \\
\hline Childcare/schools/higher education & $62(12.3)$ & $27(6.0)$ & $43(10.6)$ & $10(3.0)$ & $25(6.1)$ & $48(12.2)$ & \\
\hline Bar/restaurant & $12(2.4)$ & $10(2.2)$ & $11(2.7)$ & $23(6.9)$ & $6(1.5)$ & $7(1.8)$ & \\
\hline $\begin{array}{l}\text { Hospital/long-term care facility/ } \\
\text { healthcare worker elsewhere }\end{array}$ & $71(14.1)$ & $51(11.3)$ & $63(15.5)$ & $26(7.9)$ & $41(10.0)$ & $36(9.1)$ & \\
\hline
\end{tabular}




\begin{tabular}{|c|c|c|c|c|c|c|c|}
\hline \multirow[b]{2}{*}{ Characteristic } & $\begin{array}{l}\text { Dutch } \\
(n=503)\end{array}$ & $\begin{array}{l}\text { South-Asian } \\
\text { Surinamese } \\
(n=453)\end{array}$ & $\begin{array}{l}\text { African } \\
\text { Surinamese } \\
(n=407)\end{array}$ & $\begin{array}{l}\text { Ghanaian } \\
(n=331)\end{array}$ & $\begin{array}{l}\text { Turkish } \\
(\mathrm{n}=409)\end{array}$ & $\begin{array}{l}\text { Moroccan } \\
(n=394)\end{array}$ & \multirow[b]{2}{*}{ P value } \\
\hline & n (\%) & n (\%) & n (\%) & n (\%) & n (\%) & n (\%) & \\
\hline Missing & $0(0.0)$ & $2(0.4)$ & $0(0.0)$ & $1(0.3)$ & $2(0.5)$ & $3(0.8)$ & \\
\hline \multicolumn{8}{|l|}{ Difficulty with Dutch language $†$} \\
\hline No & NA & $348(76.8)$ & $359(88.2)$ & $41(12.4)$ & $189(46.2)$ & $211(53.6)$ & $<0.001$ \\
\hline Missing & NA & $1(0.2)$ & $2(0.5)$ & $26(7.9)$ & $14(3.4)$ & $21(5.3)$ & \\
\hline \multicolumn{8}{|l|}{ Health literacy (SBSQ) $†$} \\
\hline Adequate & $500(99.4)$ & $437(96.5)$ & $400(98.3)$ & $209(63.1)$ & $310(75.8)$ & $308(78.2)$ & $<0.001$ \\
\hline Low & $3(0.6)$ & $16(3.5)$ & $7(1.7)$ & $97(29.3)$ & $87(21.3)$ & $64(16.2)$ & \\
\hline Missing & $0(0.0)$ & $0(0.0)$ & $0(0.0)$ & $25(7.6)$ & $12(2.9)$ & $22(5.6)$ & \\
\hline Missing & $7(1.4)$ & $7(1.5)$ & $3(0.7)$ & $4(1.2)$ & $8(2.0)$ & $8(2.0)$ & \\
\hline \multicolumn{8}{|l|}{ High blood pressure ${ }^{\star *}$} \\
\hline No & $370(73.6)$ & $261(57.6)$ & $198(48.6)$ & $143(43.2)$ & $321(78.5)$ & $305(77.4)$ & $<0.001$ \\
\hline Yes & $127(25.2)$ & $185(40.8)$ & $207(50.9)$ & $181(54.7)$ & $82(20.0)$ & $81(20.6)$ & \\
\hline Missing & $6(1.2)$ & $7(1.5)$ & $2(0.5)$ & $7(2.1)$ & $6(1.5)$ & $8(2.0)$ & \\
\hline Body mass index $\left(\mathrm{kg} / \mathrm{m}^{2}\right)$, median $(\mathrm{IQR}) \dagger$ & $24(22-27)$ & $25(23-28)$ & $27(24-29)$ & $28(25-31)$ & $27(24-31)$ & $27(24-30)$ & \\
\hline
\end{tabular}

*Pearson's $\chi^{2}$ or Kruskal-Wallis test, as appropriate.

†Measured at baseline (2011-2015).

$¥$ Measured at COVID-19 visit (2020).

§Presumed higher exposure categories had priority, that is, if someone was working in a school and as a healthcare worker, they were categorised as

a healthcare worker. Caretakers were not included as a category because many had other jobs.

IBased on self-report, increased fasting glucose $(\geq 7 \mathrm{mmol} / \mathrm{L})$ or use of glucose-lowering medication.

**Based on self-report, $\mathrm{SBP} \geq 140 \mathrm{~mm} \mathrm{Hg}, \mathrm{DBP} \geq 90$ or blood pressure-lowering medication.

DBP, diastolic blood pressure; HELIUS, Healthy Life in an Urban Setting; NA, not applicable; SBP, systolic blood pressure; SBSQ, Set of Brief

Screening Question.

Figure 2 shows the adjusted seroprevalence estimates as a function of age in years for each ethnic group. In the African Surinamese group, seroprevalence decreased with age. In the Ghanaian group, the highest seroprevalence was observed between the ages of 50 and 55 years.

\section{COVID-19-related symptoms}

Online supplemental table S2 describes the SARS-CoV-2related characteristics of included participants. Of 2497 participants, $348(13.9 \%)$ suspected being infected with SARS-CoV-2, and 2144 (85.9\%) did not suspect or were unsure of being infected. $90.5 \%$ of Ghanaian participants who tested positive did not suspect or were unsure of being infected, and of them, 51.2\% reported not experiencing any COVID-19-related symptoms. SARS-CoV-2-positive individuals from other ethnic groups more frequently suspected being infected (range 59.1\%-81.8\%).

\section{Correlates of SARS-CoV-2 seropositivity per ethnic group}

Univariable analysis of correlates of SARS-CoV-2 seropositivity is presented per ethnic group in online supplemental table S3. In multivariable analysis (table 2), having a household member suspected of infection was associated with SARS-CoV-2 seropositivity in Dutch, SouthAsian Surinamese, Turkish and Moroccan participants. Recently, travelling abroad was associated with seropositivity in Dutch and South-Asian Surinamese participants. In Ghanaian participants, older age, increasing household size, living with children $\leq 3$ years old and leaving home to work and attending religious services were associated with SARS-CoV-2 seropositivity. Increased odds for SARS-CoV-2 seropositivity were also observed for living with other adults (African Surinamese), having had $\geq 2$ unique visitors in the past week (African Surinamese), leaving home to walk or exercise outside and using public transportation in the past week (Turkish participants) and occupational level (Moroccan participants).

\section{DISCUSSION}

After the first wave of the SARS-CoV-2 epidemic, we observed no evidence of ethnic disparities in the past SARS-CoV-2 infection between the six largest ethnic groups residing in Amsterdam, the Netherlands, with the noteworthy exception of individuals of Ghanaian 


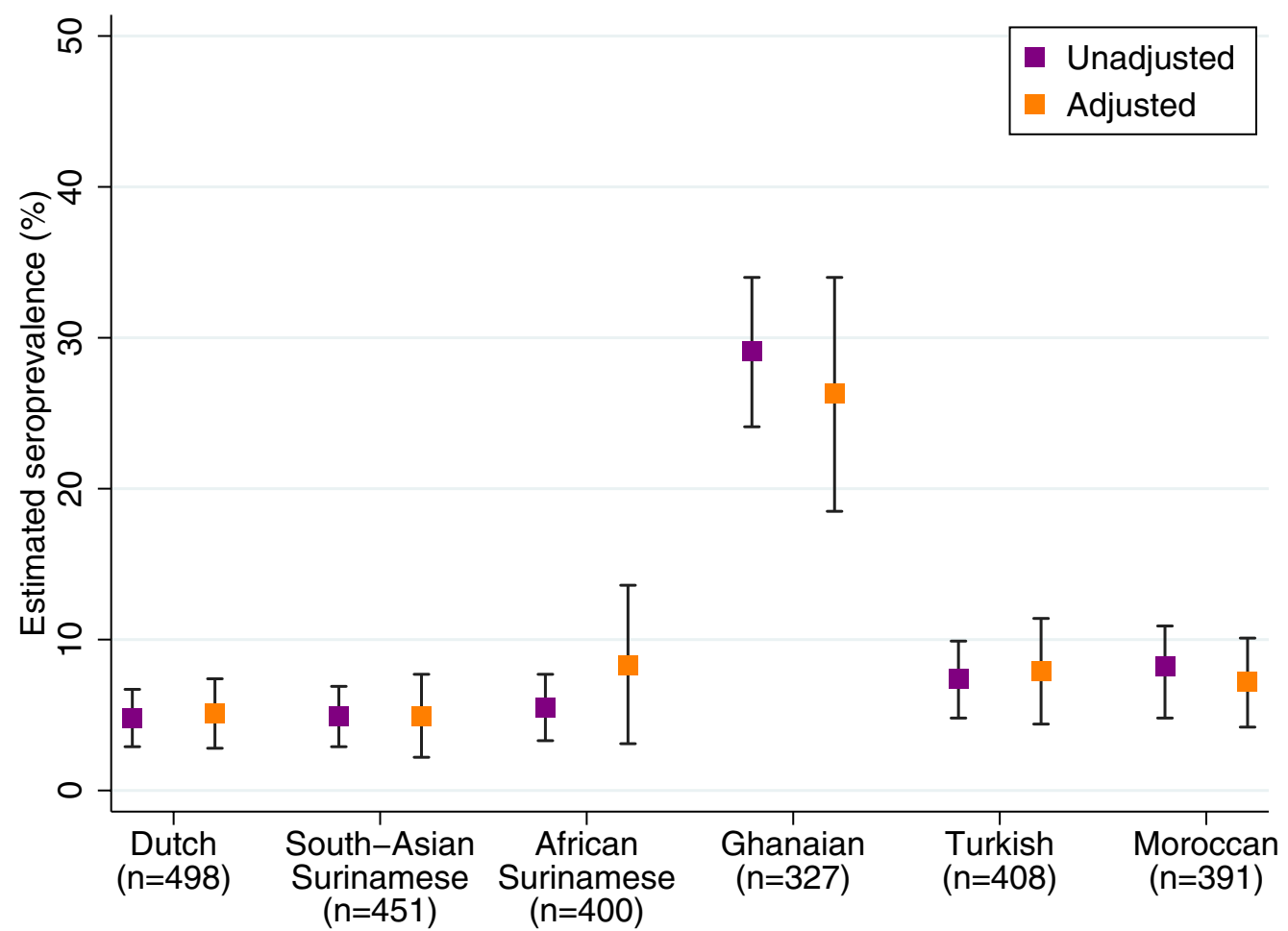

Figure 1 Unadjusted and adjusted SARS-CoV-2 seroprevalence per ethnic group ( $\mathrm{n}=2475)$, Amsterdam, the Netherlands, 24 June to 9 October 2020. We excluded individuals with an equivocal result $(n=8)$ from the seroprevalence calculation. Boxes represent the seroprevalence estimate, bands the corresponding 95\% Cl. Adjusted seroprevalence estimates were corrected for sampling, accounted for the population structure of ethnic groups in Amsterdam (ie, poststratification) and adjusted for differences in age, sex and calendar time (before/after 15 August 2020) between ethnic groups.

origin. We estimated that $26 \%$ of the adult Ghanaian group had developed SARS-COV-2 antibodies, compared with $5 \%-8 \%$ of the other adult ethnic groups. Increased risk of past infection was present among individuals who reported a household member suspected of infection in four of the six groups. Among other factors, leaving home to work and attending religious services were associated with seropositivity in Ghanaian individuals, while using public transportation was associated with seropositivity in Turkish individuals. Correlates differed between ethnicities, hence demonstrating that broad generalisations of some SARS-CoV-2-related correlates might not be appropriate for individual ethnic groups.

Among the correlates of SARS-CoV-2 seropositivity, work and travelling to work, most likely via public transportation, represents a common theme in individuals of non-Dutch origin. Working from home was one of the first preventive measures introduced in the Netherlands to mitigate spread of SARS-CoV-2. ${ }^{17}$ However, this was not feasible for individuals with lower professional levels and jobs requiring physical presence, many of whom were of non-Dutch origin. Interestingly, Moroccan individuals in the missing occupation category appeared to be more often seropositive. Previous research suggests that the health of individuals in this category resembles that of individuals with elementary or intermediary professions, ${ }^{18}$ implying that working conditions could put these individuals at risk of infection.
Although attending religious services was asked only for the past week and infections may have occurred as early as in March 2020, exposure to SARS-CoV-2 during attendance at religious services might have driven many of the past infections observed in the Ghanaian group. Religious services, along with demonstrations, were allowed to continue without a maximum number of attendees, as stipulated by Dutch law, ${ }^{19}$ which could have fostered further spread of SARS-CoV-2. Many places of worship did, however, implement social distancing measures. A nationwide study demonstrated similar findings in that Orthodox-Reformed Protestants were at increased risk for SARS-CoV-2 seropositivity during the first wave of the pandemic. ${ }^{20}$ Increased infection risk for people attending religious services has also been demonstrated in studies from other countries. ${ }^{21-23}$

Strikingly, $91 \%$ of Ghanaians with SARS-CoV-2 antibodies did not suspect or were unsure of being infected, many because they reported not experiencing any COVID-19-related symptoms. This is in stark contrast to other ethnic groups in which most SARS-CoV-2-positive individuals had suspected of being infected. If these infections were indeed asymptomatic in Ghanaians, many could have been completely unaware of their infection, and as a result might have carried out their normal routines despite unknowingly continuing transmission. The dense clustering of Ghanaians in the South-East city 

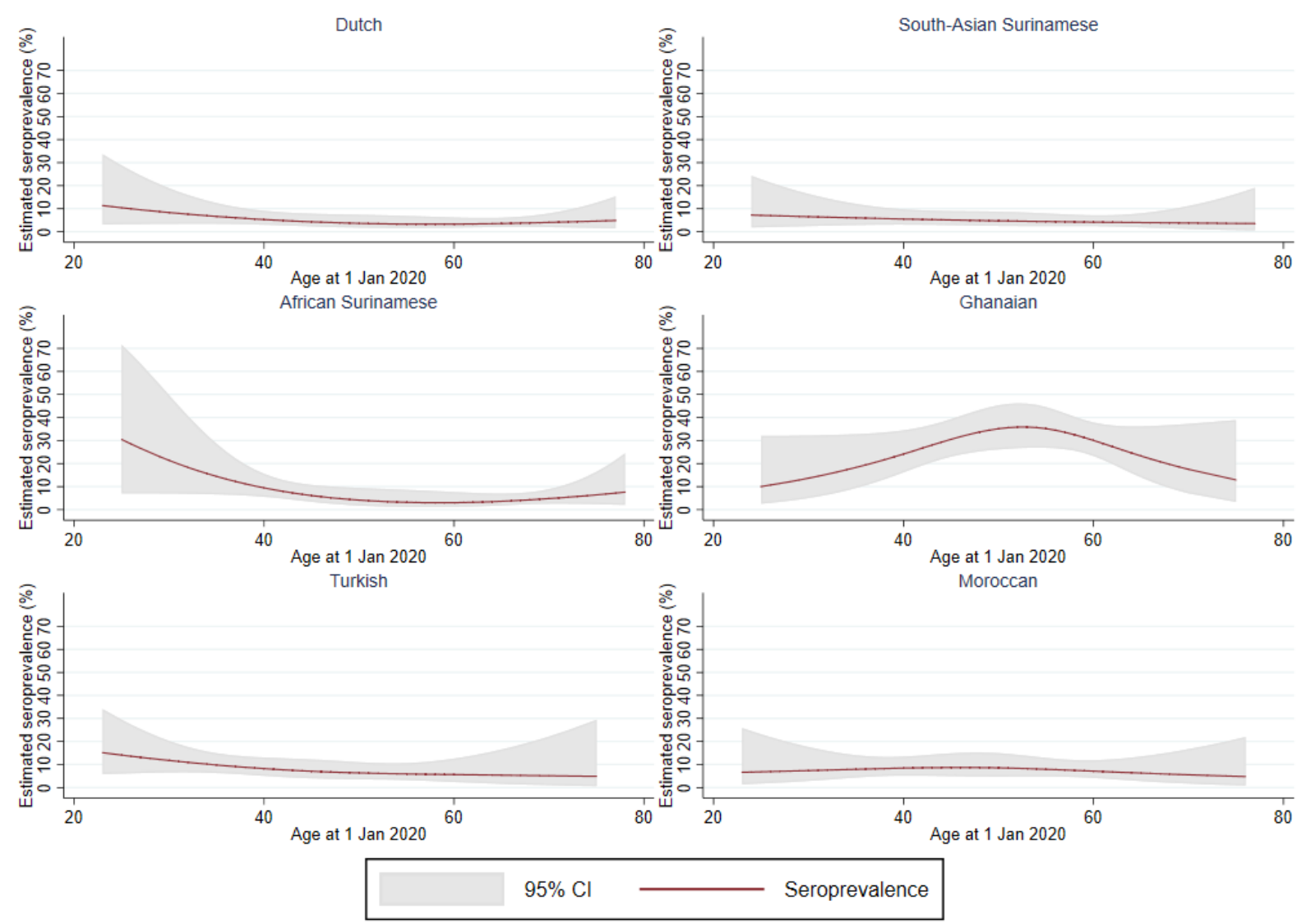

Figure 2 SARS-CoV-2 seroprevalence and age by ethnic group, Amsterdam, the Netherlands, 24 June to 9 October 2020. Seroprevalence was regressed on age (in restricted cubic splines with 3 knots) with sample and poststratification weights, within subpopulations of ethnic groups.

district of Amsterdam might have also accelerated transmission, as we unknowingly may have sampled a cluster of infections within a specific neighbourhood or religious centre. Nevertheless, there were no infection clusters within Ghanaian individuals identified during the first wave by the local Public Health Service (T Leenstra, personal communication, 27 January 2021), when SARSCoV-2 PCR testing was restricted. Our study clearly indicates that to reduce ongoing and unnoticed transmission of SARS-CoV-2, expanded testing needs to include those groups in which the proportion of asymptomatic individuals might be high or recognition of infection might be low, such as the Ghanaian residents of Amsterdam.

Since data from Ghana on SARS-CoV-2 seroprevalence and proportion of asymptomatic infection are limited, we cannot make any distinction on whether our finding reflects the epidemiology in the country of origin or is specific to Ghanaian individuals in the Netherlands. One modelling study suggests that Ghana is one of the four most affected African countries in terms of cases, but has a relatively low death rate. ${ }^{24}$ A study among Kenyan blood donors found a surprisingly high seroprevalence $(4.3 \%)$ from what can be inferred by the low number of COVID19-related hospitalisations and deaths. ${ }^{25}$ Further research is needed to clarify the role of symptom burden, earlier exposure to coronaviruses or differences in genetic vulnerability to symptoms in explaining the seemingly high proportion of asymptomatic cases in Ghanaians. ${ }^{26-29}$ Alternatively, recall of symptoms, particularly mild symptoms, could have been lower in this group, which might be explained by lower levels of health literacy, knowledge of COVID-19 symptomatology and possibly education when compared with other groups. Furthermore, selfassessment of infection might have been under-reported during the face-to-face interview due to fear of stigmatisation or social desirability bias.

Having a household member suspected of being infected was the most common and consistent determinant of seropositivity. This finding supports the observations that during periods of more extensive lockdowns, most transmissions occur in household settings and are related to symptomatic infection, age distribution and social interactions within households. ${ }^{30-32}$ Other household correlates of seropositivity were observed in specific ethnic groups and included living with other adults, living with children $\leq 3$ years old and larger household sizes.

In the Netherlands, a series of restrictions was introduced in mid-March, when the spread of SARS-CoV-2 was still limited. ${ }^{17}$ The finding that seroprevalence did not differ between ethnic groups, other than Ghanaian, 
Table 2 Correlates of SARS-CoV-2 seropositivity per ethnic group, Amsterdam, the Netherlands, 24 June to 9 October 2020 (multivariable analysis)

\begin{tabular}{|c|c|c|c|c|c|c|}
\hline & Dutch & $\begin{array}{l}\text { South-Asian } \\
\text { Surinamese }\end{array}$ & $\begin{array}{l}\text { African } \\
\text { Surinamese }\end{array}$ & Ghanaian & Turkish & Moroccan \\
\hline Characteristic & aOR $(95 \% \mathrm{Cl})$ & aOR (95\% CI) & aOR (95\% Cl) & aOR $(95 \% \mathrm{Cl})^{\star}$ & aOR (95\% Cl) & aOR (95\% Cl) \\
\hline $\begin{array}{l}\text { Per year increase in age } \\
\text { in years on } 1 \text { January } \\
2020\end{array}$ & - & - & - & 1.06 (1.03 to 1.08$)$ & - & - \\
\hline $\begin{array}{l}\text { COVID-19 substudy visit } \\
\text { after } 15 \text { August } 2020 \dagger\end{array}$ & 0.40 (0.07 to 2.38$)$ & 1.82 (0.51 to 6.48$)$ & 0.36 (0.08 to 1.57$)$ & 1.11 (0.57 to 2.15$)$ & 1.04 (0.40 to 2.72$)$ & 3.11 (1.18 to 8.23$)$ \\
\hline No & - & - & - & - & - & 1 \\
\hline Yes & - & - & - & - & - & 2.13 (0.59 to 7.67$)$ \\
\hline Missing & - & - & - & - & - & 4.54 (1.72 to 11.98$)$ \\
\hline $\begin{array}{l}\text { Per person increase in } \\
\text { household } \neq\end{array}$ & - & - & - & 1.40 (1.11 to 1.76$)$ & & \\
\hline $\begin{array}{l}\text { Household member/ } \\
\text { steady partner with } \\
\text { suspected infection† }\end{array}$ & 9.16 (2.95 to 28.43 ) & 6.27 (1.67 to 23.50$)$ & - & - & 11.20 (4.40 to 28.50$)$ & 6.00 (2.14 to 16.78$)$ \\
\hline Went to workt§ & - & - & - & 2.09 (1.10 to 3.99$)$ & - & - \\
\hline $\begin{array}{l}\text { Walked or exercised } \\
\text { outsidet§ }\end{array}$ & - & - & - & - & 4.04 (1.66 to 9.86$)$ & - \\
\hline $\begin{array}{l}\text { Attended religious } \\
\text { service†§ }\end{array}$ & - & - & - & 2.26 (1.20 to 4.25$)$ & - & - \\
\hline $\begin{array}{l}\text { Used public } \\
\text { transportation†£ }\end{array}$ & - & - & - & - & 3.02 (1.16 to 7.84$)$ & - \\
\hline $\begin{array}{l}\geq 2 \text { unique visitors at } \\
\text { homet§}\end{array}$ & - & - & 4.59 (1.61 to 13.09$)$ & - & - & - \\
\hline
\end{tabular}

Participants with an equivocal test result were excluded from this analysis. Univariable ORs are provided in online supplemental table S3. Models are adjusted for all other covariates found within the same column.

*As prevalence in the Ghanaian group was $>10 \%$, ORs could be much greater than their corresponding relative risks. The differences between these estimates are given for the univariable analysis in online supplemental table $\mathrm{S} 4$ for reference.

†Measured at COVID-19 visit (2020)

$\ddagger$ Measured at baseline (2011-2015).

$\S$ In the past week.

aOR, adjusted OR.

implies that these restrictive measures were able to prevent the spread of infection equally across ethnicities. Furthermore, additional data from individuals participating in the parent HELIUS study showed that non-ethnic Dutch groups in general were as likely as ethnic Dutch to adhere to prevention measures (F Chilunga, personal communication, 27 January 2021). It should be mentioned that our results also stem from a setting where economic inequalities are not prohibitive to healthcare access. ${ }^{33}$

In comparison to the seroprevalence estimates, people from large ethnic groups (Netherlands Antilles, Morocco, Surinam, Turkey, Ghana) had increased hospitalisation rates compared with ethnic Dutch individuals living in Amsterdam between February and May 2020, ${ }^{9}$ as shown in other settings. ${ }^{23}$ In addition, individuals with a migration background living in the Netherlands had a higher excess mortality during the first 6 weeks of the COVID-19 pandemic. ${ }^{34}$ Our data suggest that, apart from Ghanaians, the increased rates of hospitalisations and deaths in non-Dutch ethnic groups during this period cannot be explained by a higher infection rate. The severity of COVID-19 can be impacted to a large extent by underlying comorbidities, ${ }^{35}$ which vary across ethnic groups ${ }^{14}$ and could explain differences in severity. ${ }^{36}$ Healthcare inequalities, racism, stigmatisation and discrimination witnessed by ethnic minorities and differences in healthcare-seeking behaviour may provide additional explanations for these disparities. ${ }^{37-41}$

Strengths of our study include population-based sampling, with a large number of participants from the major ethnic groups living in Amsterdam, representing various levels of socioeconomic status; measuring seroprevalence via antibodies in individuals with and without previous COVID-19-related symptoms; and obtaining individual-level correlates of infection. Nonetheless, there are several limitations. First, our study includes a 
random subsample of HELIUS participants and there may be selection bias. Undocumented people and other ethnic groups living in Amsterdam were not included in the parent study. Moreover, the differential rates of lost to follow-up between ethnic groups in the parent HELIUS study might have influenced the initial selection of invited participants for the substudy. Second, participants in our substudy may have been more concerned about their health compared with non-participants. Notwithstanding the differential response rate between ethnicities in this substudy, the distribution of characteristics was largely similar between included and non-included HELIUS participants. Our estimates, corrected for sampling and poststratification, were also close to those from a nationwide study that included mainly people of Dutch origin and revealed a $6 \%$ seroprevalence among the Amsterdam population in June 2020. ${ }^{42}$ Data were also collected over a span of 4 months, which reflects different points of the epidemic, and thus the timing of testing could bias estimates. We attempted to mitigate this issue by adjusting for calendar time. Furthermore, prevention measures remained mostly the same and nationwide incidence was quite stable during this period, thereby limiting the effect of this bias. ${ }^{8}{ }^{43}$ Third, as this study was crosssectional and infection occurred in the past, it is difficult to make any causal inference with respect to correlates. Fourth, fear of stigmatisation or consequences for work might have led to an under-reporting of suspected past infection and symptoms, particularly among Ghanaians. Fifth, circulating SARS-CoV-2 antibodies could have disappeared after infection, ${ }^{44}$ although this was probably limited during the study period, ${ }^{46}{ }^{47}$ and individuals could not participate in this substudy if they were experiencing COVID-19-related symptoms, both of which likely led to underestimated seroprevalence. Finally, we used stepwise selection procedures to determine correlates of SARS-CoV-2 seropositivity, which has several limitations, including underestimated SEs. ${ }^{48}$

In conclusion, most ethnic groups displayed comparable seroprevalence after the first SARS-CoV-2 wave in Amsterdam, yet the substantially higher prevalence among the smaller Ghanaian population, possibly infections without symptoms, is of concern. Targeted prevention campaigns addressing the needs of specific ethnic groups and expanding testing opportunities are urgently warranted. In addition, prevention measures for those who cannot work from home should be intensified, also by bringing to light the employer's role in reducing COVID-19 transmissions.

\footnotetext{
Author affiliations

${ }^{1}$ Department of Infectious Diseases, Public Health Service of Amsterdam, Amsterdam, The Netherlands

${ }^{2}$ Department of Infectious Diseases, Amsterdam UMC, location AMC, Amsterdam Infection and Immunity (All), University of Amsterdam, Amsterdam, The Netherlands

${ }^{3}$ Stichting HIV Monitoring, Amsterdam, The Netherlands

${ }^{4}$ Department of Medical Microbiology, Amsterdam UMC, location AMC, University of Amsterdam, Amsterdam, The Netherlands
}

${ }^{5}$ Department of Public and Occupational Health, Amsterdam UMC, location AMC, Amsterdam Public Health Research Institute, University of Amsterdam, Amsterdam, The Netherlands

${ }^{6}$ Department of General Practice, Amsterdam UMC, location AMC, Amsterdam Public Health Research Institute, University of Amsterdam, Amsterdam, The Netherlands ${ }^{7}$ Department of Vascular Medicine, Amsterdam UMC, location AMC, Amsterdam Cardiovascular Sciences, University of Amsterdam, Amsterdam, The Netherlands ${ }^{8}$ Department of Psychiatry, Amsterdam UMC, location AMC, Amsterdam Public Health Research Institute, Center for Urban Mental Health, University of Amsterdam, Amsterdam, The Netherlands

${ }^{9}$ Department of Sociology and Anthropology, University of Amsterdam, Amsterdam, The Netherlands

${ }^{10}$ Department of Epidemiology, Health Promotion and Healthcare Innovation, Public Health Service of Amsterdam, Amsterdam, The Netherlands

${ }^{11}$ Department of Clinical Epidemiology, Biostatistics and Bioinformatics, Amsterdam UMC, location AMC, University of Amsterdam, Amsterdam, The Netherlands ${ }^{12}$ Center for Experimental Molecular Medicine, Amsterdam UMC, location AMC, University of Amsterdam, Amsterdam, The Netherlands

Acknowledgements The authors would like to acknowledge the HELIUS COVID-19 study participants for their contribution and the HELIUS team for data collection and management. They would also like to thank Anton Janssen for providing population tables.

Contributors MP, KS, JS and CA conceived, designed or oversaw the study. MP was responsible for the overall content as a guarantor. $\mathrm{HG}, \mathrm{ADMK}$ and JS were involved in the acquisition of data. $\mathrm{LC}$ and $\mathrm{AB}$ conducted the statistical analysis. $\mathrm{LC}$ $A B$ and MP drafted the manuscript. LC, AB, JS, CA, HG, ADMK, TL, EPMvC, B-JHvdB, $A L, A V, A H Z, S J, L A v V, K S$ and MP all contributed to interpretation of the data, provided feedback on the initial draft for revision and approved the final manuscript.

Funding This work was supported by ZonMw (10430022010002) and the Public Health Service of Amsterdam. The HELIUS study is conducted by Amsterdam UMC, location Academic Medical Center, and the Public Health Service of Amsterdam. Both organisations provided core support for HELIUS. The HELIUS study is also funded by the Dutch Heart Foundation (2010 T084), ZonMw (200500003), the European Union (FP-7) (278901) and the European Fund for the Integration of non-EU Immigrants (EIF) (2013EIF013).

Competing interests None declared.

Patient consent for publication Obtained.

Ethics approval This study involves human participants. Ethical approval for the HELIUS study was obtained from the Academic Medical Center Ethical Review Board (METC number 10/100, NL32251.018.10). Participants gave informed consent to participate in the study before taking part.

Provenance and peer review Not commissioned; externally peer reviewed.

Data availability statement Data are available upon reasonable request. The HELIUS data are owned by the Amsterdam UMC, location AMC, in Amsterdam, the Netherlands. Any researcher can request the data by submitting a proposal to the HELIUS Executive Board as outlined at http://www.heliusstudy.nl/en/ researchers/collaboration, by email: heliuscoordinator@amsterdamumc.nl. The HELIUS Executive Board will check the proposals for compatibility with the general objectives, ethical approvals and informed consent forms of the HELIUS study. There are no other restrictions to obtaining the data and all data requests will be processed in the same manner.

Supplemental material This content has been supplied by the author(s). It has not been vetted by BMJ Publishing Group Limited (BMJ) and may not have been peer-reviewed. Any opinions or recommendations discussed are solely those of the author(s) and are not endorsed by BMJ. BMJ disclaims all liability and responsibility arising from any reliance placed on the content. Where the content includes any translated material, BMJ does not warrant the accuracy and reliability of the translations (including but not limited to local regulations, clinical guidelines, terminology, drug names and drug dosages), and is not responsible for any error and/or omissions arising from translation and adaptation or otherwise.

Open access This is an open access article distributed in accordance with the Creative Commons Attribution Non Commercial (CC BY-NC 4.0) license, which permits others to distribute, remix, adapt, build upon this work non-commercially, and license their derivative works on different terms, provided the original work is properly cited, appropriate credit is given, any changes made indicated, and the use is non-commercial. See: http://creativecommons.org/licenses/by-nc/4.0/. 
ORCID iD

Liza Coyer http://orcid.org/0000-0001-5830-2982

\section{REFERENCES}

1 Public Health England. Disparities in the risk and outcomes of COVID-19; 2020.

2 Sze S, Pan D, Nevill CR, et al. Ethnicity and clinical outcomes in COVID-19: a systematic review and meta-analysis. EClinicalMedicine 2020;29:100630.

3 Indseth T, Grøsland M, Arnesen T, et al. COVID-19 among immigrants in Norway, notified infections, related hospitalizations and associated mortality: a register-based study. Scand J Public Health 2021;49:48-56.

4 Public Health England. Beyond the data: understanding the impact of COVID-19 on BAME groups; 2020.

5 Bhala N, Curry G, Martineau AR, et al. Sharpening the global focus on ethnicity and race in the time of COVID-19. Lancet 2020;395:1673-6.

6 Martin CA, Jenkins DR, Minhas JS, et al. Socio-demographic heterogeneity in the prevalence of COVID-19 during lockdown is associated with ethnicity and household size: results from an observational cohort study. EClinicalMedicine 2020;25:100466.

7 Statistics Netherlands (CBS). Bevolking; leeftijd, migratieachtergrond, geslacht, regio, 1 Jan 1996-2020. Available: https://opendata.cbs.nl/ statline/\#/CBS/nl/dataset/37713/table?fromstatweb [Accessed 6 Jan 2021].

8 National Institute for Public Health and the Environment, Ministry of Health, Walfare and Sport. Current information about COVID-19 (novel coronavirus), 2020. Available: https://www.rivm.nl/en/novelcoronavirus-covid-19/current-information [Accessed 6 Jan 2021].

9 Coyer L, Wynberg E, Buster M, et al. Hospitalisation rates differed by City district and ethnicity during the first wave of COVID-19 in Amsterdam, the Netherlands. BMC Public Health 2021;21:1721.

10 Government of the Netherlands. Personal records database (BRP). Available: https://www.government.nl/topics/personal-data/personalrecords-database-brp [Accessed 11 Oct 2021].

11 Niño M, Harris C, Drawve G, et al. Race and ethnicity, gender, and age on perceived threats and fear of COVID-19: evidence from two national data sources. SSM Popul Health 2021;13:100717.

12 Dodds C, Fakoya I. Covid-19: ensuring equality of access to testing for ethnic minorities. BMJ 2020;369:m2122.

13 Reiter PL, Katz ML. Racial/Ethnic differences in knowledge, attitudes, and beliefs about COVID-19 among adults in the United States. Front Public Health 2021;9:548.

14 Snijder MB, Galenkamp H, Prins M, et al. Cohort profile: the healthy life in an urban setting (HELIUS) study in Amsterdam, the Netherlands. BMJ Open 2017;7:e017873.

15 GeurtsvanKessel CH, Okba NMA, Igloi Z, et al. An evaluation of COVID-19 serological assays informs future diagnostics and exposure assessment. Nat Commun 2020;11:3436.

16 Rothman KJ. No adjustments are needed for multiple comparisons. Epidemiology 1990;1:43-6.

17 Government of the Netherlands. Nieuwe maatregelen tegen verspreiding coronavirus in Nederland, 12 March 2020. Available: https://www.rijksoverheid.nl/actueel/nieuws/2020/03/12/nieuwemaatregelen-tegen-verspreiding-coronavirus-in-nederland [Accessed 27 Jan 2021]

18 Galenkamp H, van Oers H, Stronks K. To what extent do socioeconomic inequalities in $\mathrm{SRH}$ reflect inequalities in burden of disease? The HELIUS study. J Public Health 2020;42:e412-20.

19 Government of the Netherlands. Dutch measures against coronavirus: rules that apply indoors and outdoors. Available: https:// www.government.nl/topics/coronavirus-covid-19/tackling-newcoronavirus-in-the-netherlands/public-life [Accessed 27 Jan 2021].

20 Vos ERA, den Hartog G, Schepp RM, et al. Nationwide seroprevalence of SARS-CoV-2 and identification of risk factors in the general population of the Netherlands during the first epidemic wave. J Epidemiol Community Health 2020. doi:10.1136/jech-2020215678. [Epub ahead of print: 28 Nov 2020].

21 Liu T, Gong D, Xiao J, et al. Cluster infections play important roles in the rapid evolution of COVID-19 transmission: a systematic review. Int J Infect Dis 2020;99:374-80.

22 James A, Eagle L, Phillips C, et al. High COVID-19 Attack Rate Among Attendees at Events at a Church - Arkansas, March 2020. MMWR Morb Mortal Wkly Rep 2020;69:632-5.
23 Yong SEF, Anderson DE, Wei WE, et al. Connecting clusters of COVID-19: an epidemiological and serological investigation. Lancet Infect Dis 2020;20:809-15.

24 Lukman AF, Rauf RI, Abiodun O, et al. COVID-19 prevalence estimation: four most affected African countries. Infect Dis Model 2020;5:827-38.

25 Uyoga S, Adetifa IMO, Karanja HK, et al. Seroprevalence of antiSARS-CoV-2 IgG antibodies in Kenyan blood donors. Science 2021;371:79-82.

$26 \mathrm{Ng} \mathrm{KW}$, Faulkner N, Cornish GH, et al. Preexisting and de novo humoral immunity to SARS-CoV-2 in humans. Science 2020;370:1339-43.

27 Sette A, Crotty S. Pre-existing immunity to SARS-CoV-2: the knowns and unknowns. Nat Rev Immunol 2020;20:457-8.

28 Owusu M, Sylverken AA, Ankrah ST, et al. Epidemiological profile of SARS-CoV-2 among selected regions in Ghana: a cross-sectional retrospective study. PLoS One 2020;15:e0243711.

29 Oduro-Mensah E, Tetteh J, Adomako I, et al. Clinical features of COVID-19 in Ghana: symptomatology, illness severity and comorbid non-communicable diseases. Ghana Med J 2020;54:23-32.

30 Madewell ZJ, Yang Y, Longini IM, et al. Household transmission of SARS-CoV-2: a systematic review and meta-analysis. JAMA Netw Open 2020;3:e2031756.

31 Shen M, Peng Z, Guo Y, et al. Assessing the effects of metropolitanwide quarantine on the spread of COVID-19 in public space and households. Int J Infect Dis 2020;96:503-5.

32 Sun K, Wang W, Gao L, et al. Transmission heterogeneities, kinetics, and controllability of SARS-CoV-2. Science 2021;371:eabe2424.

33 Organisation for Economic Co-operation and Development. Health for everyone? Social inequalities in health and health systems. Paris, France: OECD Health Policy Studies, 2019.

34 Kunst A, de Visser M, Stoeldraijer L, et al. Oversterfte tijdens de eerste zes weken van de corona-epidemie: Sociaal-demografische en geografische verschillen. Centraal bureau voor Statistiek, 2020. Available: https://www.cbs.nl/nl-nl/achtergrond/2020/20/oversterftetijdens-de-eerste-zes-weken-van-de-corona-epidemie

35 Wiersinga WJ, Rhodes A, Cheng AC, et al. Pathophysiology, transmission, diagnosis, and treatment of coronavirus disease 2019 (COVID-19): a review. JAMA 2020;324:782-93.

36 Raharja A, Tamara A, Kok LT. Association between ethnicity and severe COVID-19 disease: a systematic review and meta-analysis. J Racial Ethn Health Disparities 2021;8:1-10.

37 Webb Hooper M, Nápoles AM, Pérez-Stable EJ. COVID-19 and racial/ethnic disparities. JAMA 2020;323:2466-7.

38 Egede LE, Walker RJ. Structural racism, social risk factors, and Covid-19 - a dangerous convergence for black Americans. N Engl J Med 2020;383:e77.

39 Bambra C, Riordan R, Ford J, et al. The COVID-19 pandemic and health inequalities. J Epidemiol Community Health 2020;74:964.

40 Schmengler H, Ikram UZ, Snijder MB, et al. Association of perceived ethnic discrimination with general and abdominal obesity in ethnic minority groups: the HELIUS study. J Epidemiol Community Health 2017;71:453-60.

41 Suurmond J, Rosenmöller DL, El Mesbahi H, et al. Barriers in access to home care services among ethnic minority and Dutch elderly--a qualitative study. Int J Nurs Stud 2016;54:23-35.

42 National Institute for Public Health and the Environment. PIENTER corona studie: Resultaten. Available: https://www.rivm.nl/pientercorona-studie/resultaten [Accessed 22 Feb 2021].

43 Dutch Government. Vermijd drukte, houd 1,5 meter afstand 2020, 2020. Available: https://www.rijksoverheid.nl/actueel/nieuws/2020/ 05/06/vermijd-drukte-houd-15-meter-afstand [Accessed 6 Jan 2021]

44 Ibarrondo FJ, Fulcher JA, Goodman-Meza D, et al. Rapid decay of Anti-SARS-CoV-2 antibodies in persons with mild Covid-19. N Engl J Med 2020;383:1085-7.

45 Choe PG, Kim KH, Kang CK. Antibody responses 8 months after asymptomatic or mild SARS-CoV-2 infection. Emerg Infect Dis 2020;27.

46 Wajnberg A, Amanat F, Firpo A, et al. Robust neutralizing antibodies to SARS-CoV-2 infection persist for months. Science 2020;370:1227.

47 Gudbjartsson DF, Norddahl GL, Melsted P, et al. Humoral immune response to SARS-CoV-2 in Iceland. $N$ Engl J Med 2020;383:1724-34.

48 Harrell FE. Multivariable modeling strategies. In: Harrell JFE, ed. Regression modeling strategies: with applications to linear models, logistic and ordinal regression, and survival analysis. Cham: Springer International Publishing, 2015: 63-102. 